\title{
Best cut-off point of the cervical facet joint area as a new morphological measurement tool to predict cervical foraminal stenosis
}

This article was published in the following Dove Press journal:

Journal of Pain Research

\author{
Sang Joon $\mathrm{An}^{\prime}$ \\ Seok Jun Hong ${ }^{2}$ \\ Young Uk Kim ${ }^{3}$ \\ Yoon Kyung Lee ${ }^{2}$ \\ 'Department of Neurology, Catholic \\ Kwandong University, College of \\ Medicine, International ST. Mary's \\ Hospital, Incheon, Republic of Korea; \\ ${ }^{2}$ Department of Anesthesiology and Pain \\ Medicine, Kangdong Sacred Heart \\ Hospital, Hallym University, College of \\ Medicine, Seoul, Republic of Korea; \\ ${ }^{3}$ Department of Anesthesiology and Pain \\ Medicine, Catholic Kwandong University, \\ College of Medicine, International ST. \\ Mary's Hospital, Incheon, Republic of \\ Korea
}

Purpose: One of the main factor of cervical foraminal stenosis (CFS) is the hypertrophic change of the cervical facet joint. In order to analyze the connection between CFS and the facet joint hypertrophy, we devised a new morphological parameter, called the cervical facet joint cross-sectional area (CFJA). The CFJA has not yet been investigated for its association with CFS. We hypothesized that the CFJA is an important morphologic parameter in the diagnosis of CFS.

Patients and methods: All patients over 50 years of age were included. Data regarding the CFJA were collected from 160 subjects with CFS. A total of 162 control individuals underwent cervical spine magnetic resonance imaging (CMRI) as part of a routine medical examination. Axial T2-weighted CMRI images were acquired from all subjects. We used a picture archiving system to analyze the cross-sectional area of the bone margin of the cervical facet joint at the level of the most stenotic cervical spine in the axial plane.

Results: The average CFJA was $109.07 \pm 20.91 \mathrm{~mm}^{2}$ in the control group, and $126.75 \pm 22.59 \mathrm{~mm}^{2}$ in the CFS group. The CFS group was found to have significantly higher levels of the CFJA $(p<0.001)$ than the control group. ROC curve estimation was used to verify the validity of the CFJA as a new predictor of CFS. In the CFS group, the best cut off-point was $113.14 \mathrm{~mm}^{2}$, with sensitivity $=70.6 \%$, specificity $=68.6 \%$, and AUC $=0.72(95 \%$ CI, 0.66-0.77).

Conclusions: CFJA high values were closely associated with a possibility of CFS. We concluded CFJA is easy to use, fast, and useful new morphological parameter to predict CFS. Keywords: cervical facet joint hypertrophy, cervical foraminal stenosis

\section{Introduction}

Cervical foraminal stenosis (CFS) is a common cause of pain in the neck and upper extremities. ${ }^{1}$ Foramen narrowing may present as a sharp arm or neck pain, paraesthesia, numbness, or tingling sensation with symptoms spreading to the distal portion of the arms. Compression or irritation of the cervical nerve root as it travels through a neural foramen causes cervical radiculopathy. ${ }^{2-4}$ Motor symptoms such as weakness may sometimes accompany sensory symptoms in aggravated narrowing. ${ }^{5-7}$ Cervical spine magnetic resonance imaging (CMRI) is the most sensitive technique for detecting early morphological changes in the cervical spine. $^{3,8}$ An accurate CMRI diagnosis of CFS is critical to determine appropriate treatment and to exclude the possibility of peripheral neuropathy. ${ }^{3,9}$ Clinical care of patients with CFS is determined based on neurological symptoms with CMRI studies. ${ }^{5}$ Various anatomical factors can induce CFS. These include disc herniation,
Department of Anesthesiology and Pain Medicine, Catholic Kwandong University, College of Medicine, International ST.

Mary's Hospital, Simgokro I00Gil 25 Seogu, Incheon City 227II, Republic of Korea Tel +82 1032436643

Fax +82322903568

Email uk20I@hanmail.net
Journal of Pain Research 2019:12 1325-1330

1325

DovePress $f$ in $\boldsymbol{v}$

http://doi.org/10.2147/IPR.S204567 
osteophyte formation, and loss of disc height, all of which can be evaluated by CMRI. ${ }^{9-13}$ Cervical facet joint hypertrophy is also considered main cause of CFS. ${ }^{14}$ Hypertrophic changes of the cervical facet is induced by cervical degenerations. ${ }^{14}$ Chaput et al demonstrated that patients with cervical spine degeneration have more asymmetric facet hypertrophy and greater total facet area, on axial supine imaging. ${ }^{15} \mathrm{Kim}$ et al reported that the cervical spine foraminal narrowing is associated with degenerative facet joint hypertrophy, mechanical compression of the nerve root can be the result of these anatomic changes. ${ }^{1}$ However, they did not evaluate the role of the crosssectional area of the cervical facet joint as a morphological parameter of CFS. Therefore, we devised a new morphological parameter, called the cervical facet joint cross-sectional area (CFJA), in order to evaluate the connection between CFS and hypertrophy of the cervical facet joint. To the best of our knowledge, the CFJA has not yet been evaluated for its association with CFS. We hypothesized that the CFJA is an important morphologic parameter in the diagnosis of CFS. Therefore, we compared the CFJA between CFS patients and normal controls using axial T2- weighted CMRI.

\section{Patients and methods}

\section{Patients}

This research protocol was approved and reviewed by the Catholic Kwandong University, International St Mary`s hospital, College of Medicine, Republic of Korea, Incheon, Institutional Review Board (IRB) (IRB protocol number: IS18RISI0016). Written informed consent was obtained from each patients involved in this original research. This research followed the Declaration of Helsinki in confidentiality of patient data. We reviewed patients who underwent CMRI between April 2016 and August 2018 and had been diagnosed with CFS. We only included subjects over age 50 if they clinically had manifestations compatible with CFS, the most stenosis at C5/6, and CMRI performed within one year of the diagnosis that was available for chart review. This research excluded patients who had histories of previous cervical spine surgery, spinal cord injury, cervical congenital spine defects, space occupying lesions (such as tumors or cysts), stroke and syringomyelia.

A total of 160 subjects were enrolled after the CFS diagnosis was confirmed by two board-certified, experienced radiologists. In the CFS group, there were 96 (60\%) males and $64(40 \%)$ females with a mean age of 58.36 \pm 7.13 years (range: $50-81$ years; see the Table 1 ). In order to compare the CFJA between subjects with and without CFS, we enrolled a group of control subjects who had undergone a CMRI as a part of medical check-up and who had no CFS-related symptoms and signs. The control group consisted of 162 subjects (76 males [46.91\%] and 86 females [53.09\%]) with a mean age of 57.38 \pm 6.96 years (range: $50-79$ years; see the Table 1). This research also examined the $\mathrm{CFJA}$ in the control group at the $\mathrm{C} 5 / 6$ facet joint level.

\section{Imaging parameters}

The CMRI analysis had been performed with Avanto 3T MRI scanner (Siemens Healthcare). Axial T2-weighted cervical spine images with four mm thick slices had been acquired. The parameters that were used are as follows: 0.4-mm intersection gap, 607-ms/15-ms repetition time (TR)/echo time (TE), 15 echo train length (ETL), and $160 \times 160 \mathrm{~cm}$ field of view, $320 \times 224$ matrix.

\section{Image analysis}

The axial T2-weighted cerival spine images at the level of facet joint for all subjects had been acquired. We measured the CFJA at the cervical facet joints on the MRI using a picture archiving system (INFINITT Healthcare Co., Seoul, Korea). We measured the CFJA as the crosssectional area by cervical the facet joint at C5/6 (Figure 1).

\section{Statistical analysis}

Values were expressed as means \pm standard deviations (SD). We compared the results of CFJA between the control and CFS groups using an unpaired Student's $t$-test. The word

Table I Comparison of the baseline demographic data of CFS and control group

\begin{tabular}{|l|l|l|l|}
\hline Variable & $\begin{array}{l}\text { Control } \\
\text { Group } \\
\mathbf{n = 1 6 2}\end{array}$ & $\begin{array}{l}\text { CFS } \\
\text { Group } \\
\mathbf{n = 1 6 0}\end{array}$ & $\begin{array}{l}\text { Statistical } \\
\text { significance }\end{array}$ \\
\hline $\begin{array}{l}\text { Gender (male/ } \\
\text { female) }\end{array}$ & $76 / 86$ & $96 / 64$ & NS \\
Age (yrs) & $57.38 \pm 6.96$ & 58.36 & NS \\
& $109.07 \pm 20.91$ & $\begin{array}{l}126.75 \\
\pm 22.59\end{array}$ & $p<0.001$ \\
\hline
\end{tabular}

Notes: Data represent the mean \pm standard deviation (SD), NS = not statistically significant.

Abbreviations: CFS, cervical foraminal stenosis; CFJA, cervical facet joint crosssectional area. 

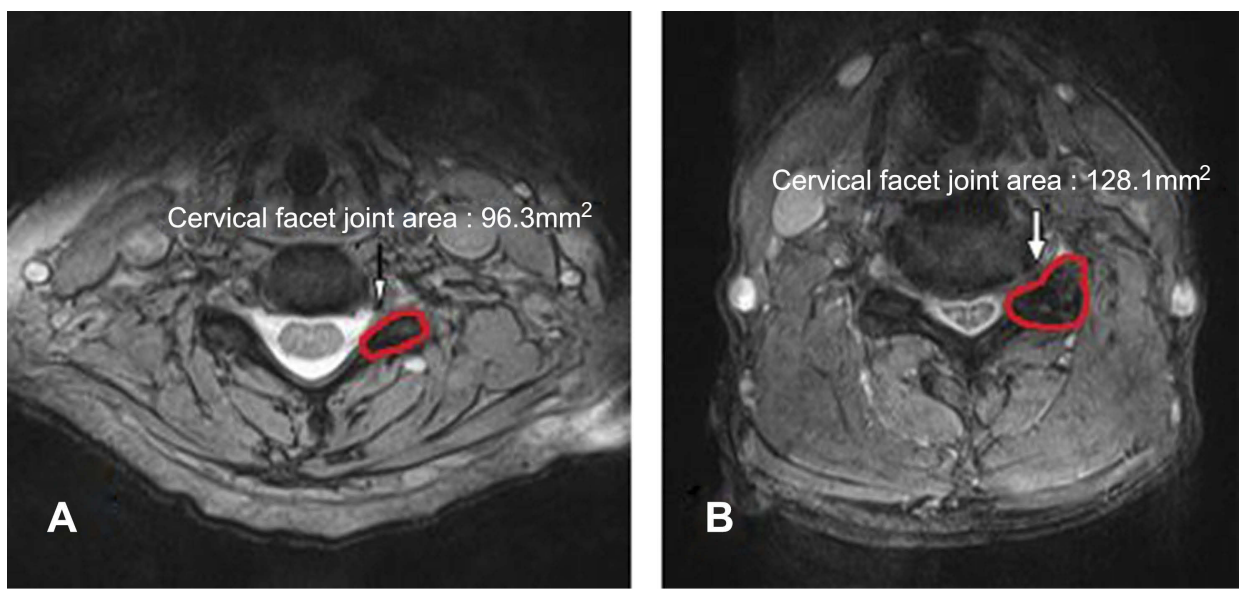

Figure I Measurement of the cervical facet joint cross-sectional area on CMRI at the most stenotic cervical level. (A) Control group. (B) Cervical foraminal stenosis group.

"significant" will be used to refer to relations where $p$-values $<0.05$. The correlation between the age-related changes in the elderly and CFJA were analyzed using a oneway ANOVA. The ROC curve estimation was used to verify the validity of the CFJA as a new predictor of CFS. The statistical analysis was performed with an SPSS version 22 for Windows (IBM SPSS, IBM Corp, New York).

\section{Results}

The demographic characteristics were not significantly different between the control group and the CFS group (Table 1). The average CFJA was $109.07 \pm 20.91 \mathrm{~mm}^{2}$ in the control group, and $126.75 \pm 22.59 \mathrm{~mm}^{2}$ in the CFS group. CFS subjets had significantly higher CFJA $(p<0.001)$ than control groups (Table 1). The average CFJA of the control subjects was $108.32 \pm 20.19 \mathrm{~mm}^{2}$ in subjects aged $50-59$ years, $106.12 \pm 22.51 \mathrm{~mm}^{2}$ in subjects aged $60-69$ years, and $124.68 \pm 17.83 \mathrm{~mm}^{2}$ in subjects in the 70-79 age group (Table 2). We found statistically significant differences in the control group between the CFJA and age-related differences in the one-way ANOVA $(\mathrm{F}=3.894 ; \mathrm{df}=2 ; p=0.022)$. The mean CFJA of the CFS group measured $128.09 \pm 22.58 \mathrm{~mm}^{2}$ in patients aged $50-59,125.64 \pm 24.29 \mathrm{~mm}^{2}$ in patients in the $60-69$ age

Table 2 Age distribution of patients with mean CFJA of control group

\begin{tabular}{|l|l|}
\hline Age distribution (years) & Total $(\mathbf{N})$ \\
\hline $50-59$ & $108.32 \pm 20.19 \mathrm{~mm}^{2}(\mathrm{II})$ \\
$60-69$ & $106.12 \pm 22.51 \mathrm{~mm}^{2}(34)$ \\
$70-79$ & $124.68 \pm 17.83 \mathrm{~mm}^{2}(12)$ \\
\hline
\end{tabular}

Abbreviations: CFJA, cervical facet joint cross-sectional area; CFS, cervical foraminal stenosis.
Table 3 Age distribution of patients with mean CFJA of CFS group

\begin{tabular}{|l|l|}
\hline Age distribution (years) & Total (N) \\
\hline $50-59$ & $128.09 \pm 22.58 \mathrm{~mm}^{2}(112)$ \\
$60-69$ & $125.64 \pm 24.29 \mathrm{~mm}^{2}(32)$ \\
$70-81$ & $119.60 \pm 17.15 \mathrm{~mm}^{2}(16)$ \\
\hline
\end{tabular}

Abbreviations: CFJA, cervical facet joint cross-sectional area; CFS, cervical foraminal stenosis.

group, and $119.60 \pm 17.15 \mathrm{~mm}^{2}$ in patients in the $70-81$ age category (Table 3 ). In the CFS group, we did not find any statistically significant relationships between CFJA and age-related differences ( $\mathrm{F}=1.049 ; \quad \mathrm{df}=2 ; \quad p=0.353)$. Regarding the validity of the CFJA as predictors of CFS, the ROC curve estimation revealed that the best cut-off score of the CFJA was $113.14 \mathrm{~mm}, 1$ with $70.6 \%$ sensitivity, $68.6 \%$ specificity, and AUC of $0.72(95 \% \mathrm{CI}$, 0.66-0.77) (Table 4, Figure 2).

\section{Discussion}

We demonstrated that CFJA high values were closely associated with a possibility of CFS. CFS is caused by the narrowing of cervical nerve roots at the entrance of cervical foramen and is seen commonly. Significant narrowing of the cervical foramen may present as a sharp arm or neck pain, paresthesia, numbness or tingling sensation with or without symptoms spreading to the distal portion of the upper extremities. ${ }^{2,5}$ In order to exclude the possibility of other diseases and to determine appropriate treatment, an accurate CMRI diagnosis of CFS is essential. ${ }^{3,16}$ CFS is caused by the compression of the cervical nerve roots, commonly a result of lateral disc herniation or degenerative osteophytes. ${ }^{17-19} \mathrm{Kim}$ et $\mathrm{al}^{11}$ have reported 
Table 4 Sensitivity and specificity of each cut-off point of the CFJA

\begin{tabular}{|c|c|c|}
\hline CFJA $\left(\mathrm{mm}^{2}\right)$ & Sensitivity (\%) & Specificity (\%) \\
\hline 80.53 & 100 & 7.4 \\
\hline 95.41 & 95.6 & 25.9 \\
\hline 104.45 & 83.8 & 41.4 \\
\hline $113.14^{\mathrm{a}}$ & 70.6 & 68.6 \\
\hline 123.13 & 50.6 & 78.4 \\
\hline 138.07 & 26.9 & 92.0 \\
\hline
\end{tabular}

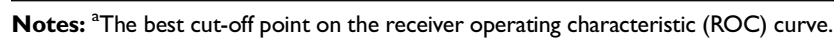
Abbreviation: CFJA, cervical facet joint cross-sectional area.

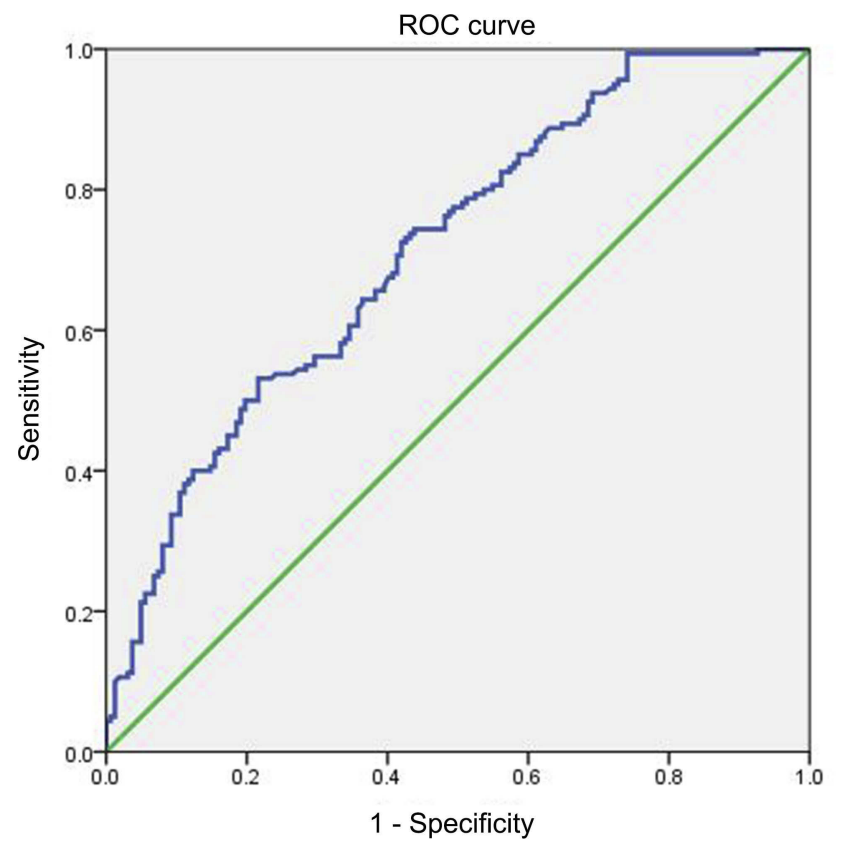

Figure 2 Receiver operating characteristic curve of cervcal facet joint crosssectional area for prediction of cervical foraminal stenosis. The best cut off point of CFJA was $113.14 \mathrm{~mm} 2$, with sensitivity $70.6 \%$, specificity $68.6 \%$, and AUC 0.72 . CFJA AUC $(95 \% \mathrm{Cl})=0.72(0.66-0.77)$.

Abbreviations: CFJA, cervical facet joint cross-sectional area; AUC, area under the curve.

a new grading system based on $\mathrm{T} 2$ weighted axial images and the classification of CFS using 3 grades. These grade systems are calculated from the ratio of the narrowest width of the extraforaminal nerve root to the width of neural foramen in the cervical region. Park et $\mathrm{al}^{20}$ have introduced another grading system using oblique images, which allows for the analysis of narrowed neural foramen. Park's grades are a morphological diagnosis based on the perineural fat obliteration. They divided CFS using 4 grades. Besides, various CMRI grading systems for CFS have been reported, and most of them are based on the evaluation of oblique sagittal or axial images. ${ }^{21,22}$ However, discrepancies are sometimes encountered in the
CFS grading according to the reference imaging plane. ${ }^{11}$ We think these previous grading systems may have overlooked cervical facet joint hypertrophy. The cervical facet degenerative changes are thought to lead to hypertrophic changes. Morishita et $\mathrm{al}^{23}$ have identified hypertrophic changes of the cervical facet joint at the middle level of the cervical column. Hypertrophic changes were seen more often in men and tended to be unilateral. Citow et $\mathrm{al}^{24}$ have presented the compression of the vertebral artery due to a unilateral hypertrophy arising from the C6 superior facet. Yamahata et al insisted that the compression of the vertebral artery was caused by an excessive bone hypertrophy at the C6 superior facet. ${ }^{14}$ Goel et al described some patients with facet hypertrophy at the atlantal bone. $^{25}$ Another cause of facet joint hypertrophy has been reported by Kirby et $\mathrm{al}^{26}$. They insisted that cervical facet joint hypertrophy can stem from whiplash injuries of the cervical column, which results in a muscular sprain of facet joints with periosteal tearing, and this can lead to hypertrophic change.

Chaput et al have demonstrated that facet joint morphology may predict possible cervical degenerative spondylolisthesis. ${ }^{15} \mathrm{Kim}$ et al have reported that CFS is defined by neural foraminal narrowing that may be caused by cervical facet hypertrophy. ${ }^{27}$ However, previous researches did not evaluate the role of the crosssectional area of the cervical facet joint as a morphological parameter of CFS. Therefore, we devised a morphological parameter, called the cervical facet joint cross-sectional area (CFJA), in order to evaluate the connection between CFS and hypertrophy of the cervical facet joint. To the best of our knowledge, the CFJA has not yet been evaluated for its association with CFS. We hypothesized that the CFJA is an important morphologic parameter in the diagnosis of CFS. And we finally demonstrated the positive correlation between CFS and CFJA. In the current study, we found that the CFJA had 70.6\% sensitivity, $68.6 \%$ specificity, and AUC of 0.72 (95\% CI, 0.66-0.77) to predict CFS. Therefore, our findings suggest that CFJA is an accurate and objective morphological parameter for CFS prediction. Our study only included individuals aged above 50 years because Rong et al have demonstrated that around 30\% of the facet joints in patients older than 50 were degenerated, whereas only $10 \%$ of the facet joints in patients younger than 50 were degenerated. ${ }^{28}$ We also found statistically significant difference between the CFJA and age-related differences. This research may be limited 
by a number of factors. First, even though we measured the CFJA at the C5/6 facet joint level, there may be mistakes associated with taking these measurements on the CMRI because axial images in the cervical spine may be inhomogeneous due to different cutting angle of the CMRI resulting from posture in patients and individual anatomic variations. Additionally, the four $\mathrm{mm}$ slice of MR images are thicker than an ideal image analysis. Second, baseline factors of the patient population, such as height and weight, varied widely. Third, this study only investigated CFJA, even though there are several different methods that are known to effectively discriminate CFS, such as the width of the neural foramen, ${ }^{21,27}$ the width of the extraforaminal nerve root (CF7), and canal or neural foraminal encroachment. $^{29-31}$ Fourth, this research is of a retrospective study. Prospective studies are needed to repeat and validate our research. Fifth, it could be interesting to investigate the association with the symptoms of the patients, for example, neck disability index, or visual analogue scale in the future work. Despite these limitations, this research is the first analysis to document the association of CFJA with CFS. These results may provide a reliable assessment of CFS.

\section{Conclusion}

CFJA is a sensitive parameter for the diagnosis of CFS with a best cut off-point of $113.14 \mathrm{~mm}^{2}$, a sensitivity of $70.6 \%$, a specificity of $68.6 \%$, and an AUC of 0.72 . We concluded CFJA is easy to use, fast, and useful new morphological parameter to predict CFS.

\section{Author contributions}

All authors contributed to data analysis, drafting or revising the article, gave final approval of the version to be published, and agree to be accountable for all aspects of the work. Young Uk Kim and Yoon Kyung Lee contributed equally to this article as co-corresponding authors.

\section{Disclosure}

All authors report no conflicts of interest in this work.

\section{References}

1. Kim MS, Lee DG, Chang MC. Outcome of transforaminal epidural steroid injection according to severity of cervical foraminal stenosis. World Neurosurg.

2. Corey DL, Comeau D. Cervical radiculopathy. Med Clin North Am. 2014;98(4):791-799, xii. doi:10.1016/j.mcna.2014.04.001
3. Lee JE, Park HJ, Lee SY, et al. Interreader reliability and clinical validity of a magnetic resonance imaging grading system for cervical foraminal stenosis. J Comput Assist Tomogr. 2017;41(6):926-930. doi:10.1097/RCT.0000000000000628

4. Kim JS, Ko JS, Bang S, Kim H, Lee SY. Cervical plexus block. Korean J Anesthesiol. 2018;71(4):274-288. doi:10.4097/kja. d. 18.00143

5. Lee KH, Park HJ, Lee SY, et al. Comparison of two MR grading systems for correlation between grade of cervical neural foraminal stenosis and clinical manifestations. $B r \quad J$ Radiol. 2016;89 (1062):20150971. doi:10.1259/bjr.20150971

6. Chae YJ, Han KR, Park HB, Kim C, Nam SG. Paraplegia following cervical epidural catheterization using loss of resistance technique with air: a case report. Korean J Anesthesiol. 2016;69(1):66-70. doi:10.4097/kjae.2016.69.1.66

7. Lee JY, Kim DK, Jung DW, Yang JY, Kim DY. Analysis of medical disputes regarding chronic pain management in the 2009-2016 period using the Korean Society of Anesthesiologists database. Korean J Anesthesiol. 2017;70(2):188-195. doi:10.4097/kjae.2017.70.2.188

8. Kaiser JA, Holland BA. Imaging of the cervical spine. Spine (Phila Pa 1976). 1998;23(24):2701-2712.

9. Yousem DM, Atlas SW, Goldberg HI, Grossman RI. Degenerative narrowing of the cervical spine neural foramina: evaluation with high-resolution 3DFT gradient-echo MR imaging. AJNR Am J Neuroradiol. 1991;12(2):229-236.

10. Abbed KM, Coumans JV. Cervical radiculopathy: pathophysiology, presentation, and clinical evaluation. Neurosurgery. 2007;60(1 Supp1 1):S28-S34. doi:10.1227/01.NEU.0000249223.51871.C2

11. Kim W, Ahn KS, Kang CH, Kang WY, Yang KS. Comparison of MRI grading for cervical neural foraminal stenosis based on axial and oblique sagittal images: concordance and reliability study. Clin Imaging. 2017;43:165-169. doi:10.1016/j.clinimag. 2017.03.008

12. Hong JH, Lee MY, Jung SW, Lee SY. Does spinal stenosis correlate with MRI findings and pain, psychologic factor and quality of life? Korean J Anesthesiol. 2015;68(5):481-487. doi:10.4097/ kjae.2015.68.5.481

13. Chhabra S, Singhal SK, Mohammed S, Biyani G, Pandey R. Sedation in a child with Klippel-Feil syndrome scheduled for magnetic resonance imaging. Korean J Anesthesiol. 2018;71(2):163-164. doi:10.4097/kjae.2018.71.2.163

14. Yamahata H, Yasuda M, Aoyama T, Osuka K, Arita K, Takayasu M. Cervical radiculopathy due to disc herniation with adjacent facet hypertrophy: case report. Neurol Med Chir (Tokyo). 2014;54 (9):757-760.

15. Chaput CD, Allred JJ, Pandorf JJ, Song J, Rahm MD. The significance of facet joint cross-sectional area on magnetic resonance imaging in relationship to cervical degenerative spondylolisthesis. Spine J. 2013;13(8):856-861. doi:10.1016/j.spinee.2013.01.021

16. Kannan S, Surhonne NS, Ck R, B K, Dr D, Sr R. Effects of bilateral superficial cervical plexus block on sevoflurane consumption during thyroid surgery under entropy-guided general anesthesia: a prospective randomized study. Korean J Anesthesiol. 2018;71 (2):141-148. doi:10.4097/kjae.2018.71.2.141

17. Argentieri EC, Koff MF, Breighner RE, Endo Y, Shah PH, Sneag DB. Diagnostic accuracy of zero-echo time MRI for the evaluation of cervical neural foraminal stenosis. Spine (Phila Pa 1976).

18. Douglas-Akinwande AC, Rydberg J, Shah MV, et al. Accuracy of contrast-enhanced MDCT and MRI for identifying the severity and cause of neural foraminal stenosis in cervical radiculopathy: a prospective study. AJR Am J Roentgenol. 2010;194(1):55-61. doi:10.2214/AJR.09.2988

19. Kim KS, Kim YK, Kim SS, Shim SM, Cho HJ. Cerebrospinal fluid infection after lumbar nerve root steroid injection: a case report. Korean J Anesthesiol. 2017;70(1):90-94. doi:10.4097/kjae.2017.70. 1.90 
20. Park HJ, Kim SS, Lee SY, et al. A practical MRI grading system for cervical foraminal stenosis based on oblique sagittal images. $\mathrm{Br}$ J Radiol. 2013;86(1025):20120515. doi:10.1259/bjr.20120515

21. Bartlett RJ, Hill CR, Gardiner E. A comparison of T2 and gadolinium enhanced MRI with CT myelography in cervical radiculopathy. $\mathrm{Br}$ J Radiol. 1998;71(841):11-19. doi:10.1259/bjr.71.841.9534693

22. Song KJ, Choi BW, Kim GH, Kim JR. Clinical usefulness of CT-myelogram comparing with the MRI in degenerative cervical spinal disorders: is CTM still useful for primary diagnostic tool? J Spinal Disord Tech. 2009;22(5):353-357. doi:10.1097/ BSD.0b013e31817df78e

23. Morishita K, Kasai Y, Uchida A. Hypertrophic change of facet joint in the cervical spine. Med Sci Monit. 2008;14(2):CR62-CR64.

24. Citow JS, Macdonald RL. Posterior decompression of the vertebral artery narrowed by cervical osteophyte: case report. Surg Neurol. 1999;51(5):495-498; discussion 498-499.

25. Goel A, Bonde V, Menon R. Unilateral atlantal lateral mass hypertrophy. Report of four cases. J Neurosurg Spine. 2006;4(4):334-337. doi:10.3171/spi.2006.4.4.334

26. Kirby NG, Maimaris C. Unilateral facet joint hypertrophy causing nerve root irritation. Ann $R$ Coll Surg Engl. 1989;71 (4):267-268.
27. Kim S, Lee JW, Chai JW, et al. A new MRI grading system for cervical foraminal stenosis based on axial T2-weighted images. Korean J Radiol. 2015;16(6):1294-1302. doi:10.3348/kjr.2015.16.6.1294

28. Rong X, Liu Z, Wang B, Pan X, Liu H. Relationship between facet tropism and facet joint degeneration in the sub-axial cervical spine. BMC Musculoskelet Disord. 2017;18(1):86. doi:10.1186/s12891-0171624-z

29. Ryan AG, Morrissey BM, Newcombe RG, Halpin SF, Hourihan MD. Are T1 weighted images helpful in MRI of cervical radiculopathy? Br J Radiol. 2004;77(915):189-196. doi:10.1259/ bjr/97837637

30. Iwata T, Mitoro M, Kuzumoto N. Feasibility of early and repeated low-dose interscalene brachial plexus block for residual pain in acute cervical radiculopathy treated with NSAIDS. Korean J Pain. 2014;27:125-132. doi:10.3344/kjp.2014.27.2.125

31. Jeon YH, Kim SY. Detection rate of intravascular injections during cervical medial branch blocks: a comparison of digital subtraction angiography and static images from conventional fluoroscopy. Korean J Pain. 2015;28:105-108. doi:10.3344/ kjp.2015.28.2.105

\section{Publish your work in this journal}

The Journal of Pain Research is an international, peer reviewed, open access, online journal that welcomes laboratory and clinical findings in the fields of pain research and the prevention and management of pain. Original research, reviews, symposium reports, hypothesis formation and commentaries are all considered for publication. The manuscript management system is completely online and includes a very quick and fair peer-review system, which is all easy to use. Visit http:// www.dovepress.com/testimonials.php to read real quotes from published authors. 